\title{
Gold Nanorod-Based Engineered Cardiac Patch for Suture-Free Engraftment by Near IR
}

\author{
Maayan Malki, ${ }^{\dagger, \ddagger, \#}$ Sharon Fleischer, ${ }^{\ddagger, \S, \#}$ Assaf Shapira, ${ }^{\ddagger, \S, \|}$ and Tal Dvir ${ }^{*}, \dagger, \ddagger, \S, \| \odot$ \\ ${ }^{\dagger}$ The Department of Materials Science and Engineering, Faculty of Engineering, Tel Aviv University, Tel Aviv 6997801, Israel \\ ¥The Center for Nanoscience and Nanotechnology, Tel Aviv University, Tel Aviv 6997801, Israel

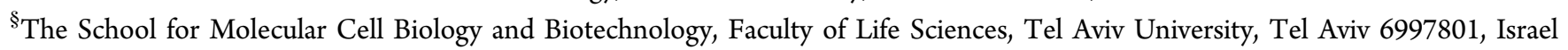 \\ "Sagol Center for Regenerative Biotechnology, Tel Aviv University, Tel Aviv 6997801, Israel
}

\section{Supporting Information}

\begin{abstract}
Although cardiac patches hold a promise for repairing the infarcted heart, their integration with the myocardium by sutures may cause further damage to the diseased organ. To address this issue, we developed facile and safe, suture-free technology for the attachment of engineered tissues to organs. Here, nanocomposite scaffolds comprised of albumin electrospun fibers and gold nanorods (AuNRs) were developed. Cardiac cells were seeded within the scaffolds and assembled into a functioning patch. The engineered tissue was then positioned on the myocardium and irradiated with a near IR laser $(808 \mathrm{~nm})$. The AuNRs were able to absorb the light and convert it to thermal energy, which locally changed the molecular structure of the fibrous scaffold, and strongly, but safely, attached it to the wall of the heart. Such hybrid biomaterials can be used in the future to integrate any engineered tissue with any defected organs, while minimizing the risk of additional injury for the patient, caused by the conventional stitching methods.
\end{abstract}

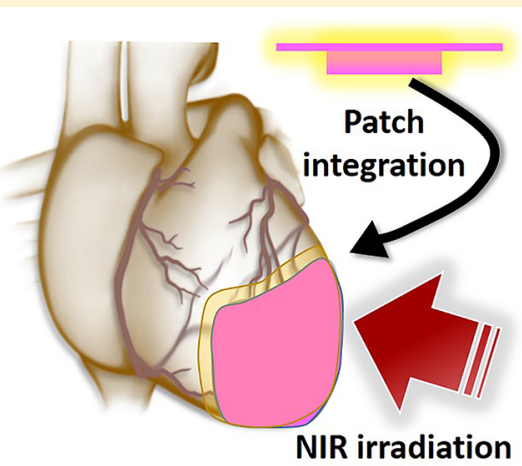

KEYWORDS: Cardiac tissue engineering, engraftment, near IR, tissue integration, gold nanorods

$\mathrm{E}$ ngineered cardiac patches are considered a promising approach for regenerating the infarcted heart. ${ }^{1,2}$ In this concept, cardiac cells are seeded within 3-dimensional (3D) biomaterial scaffolds, which provide a physical, structural, and biochemical supporting microenvironment. The scaffolds encourage cell-cell and cell-matrix interactions, which lead to the formation of a functioning tissue. ${ }^{3}$ Once the cardiac patches are engineered, they are usually attached to the scar tissue of the heart by a surgical operation, involving synthetic sutures or staples. ${ }^{4,5}$ Although these surgical procedures can strongly attach a patch to a desired site, several limitations still remain. These include the blockage of blood supply to the patch, bleeding, injury to a healthy tissue, and risk of infection. Such trauma may cause an additional deterioration of the left ventricle's function, expanding the damage.

In recent years, in order to attach tissues, several alternatives to surgical procedures were used. ${ }^{6-9}$ For example, biological glues, such as medical grade cyanoacrylates were used to adhere tissues in the stomach. Although, the materials strongly adhere to tissues, they are associated with toxicity. ${ }^{10}$ In addition, the strong adhesion leads to an area with stiff mechanical properties, which do not match the elastic properties of the myocardium, ${ }^{11}$ impeding proper contractile function and provoking inflammation. To address this limitation, several biological glues were developed. ${ }^{12-17}$ For example, an elegant elastomeric biodegradable and biocompatible, gecko-inspired tissue adhesive tape was developed. ${ }^{18}$ The glue relied on the synergy between chemistry and topography, showing an effective sealing of surgical colon and stomach defects. In another study, a nanoparticle solution was used to glue two hydrogels by connecting to their polymer chains and reorganizing their structure. ${ }^{19}$ Other approaches include neat glues that do not contain any solvents, and their mechanical properties can be tuned. ${ }^{20}$ However, although all these materials exhibit excellent adhesive properties, several properties limit their application for engineering thick tissues. For example, they are not porous, do not supply a supporting fibrous biomimetic microenvironment for tissue assembly, and in some cases their water-free environment does not allow cell penetration into their core.

Gold nanostructures can also be used for tissue welding and wound sealing. For example, gold nanoshells or particles can strongly absorb light, heat up and locally melt tissues, and fuse them. ${ }^{21,22}$ However, such technologies were designed to fuse tissues by heating without a special consideration for cell viability. In addition, the particles are in a solution and a 3D assembly of tissues within is limited.

Recently, we have shown that gold nanostructures such as spheres or particles with a higher aspect ratio can be incorporated into $3 \mathrm{D}$ scaffolds to increase the transfer of the

Received: November 21, 2017

Revised: January 22, 2018

Published: February 6, 2018 


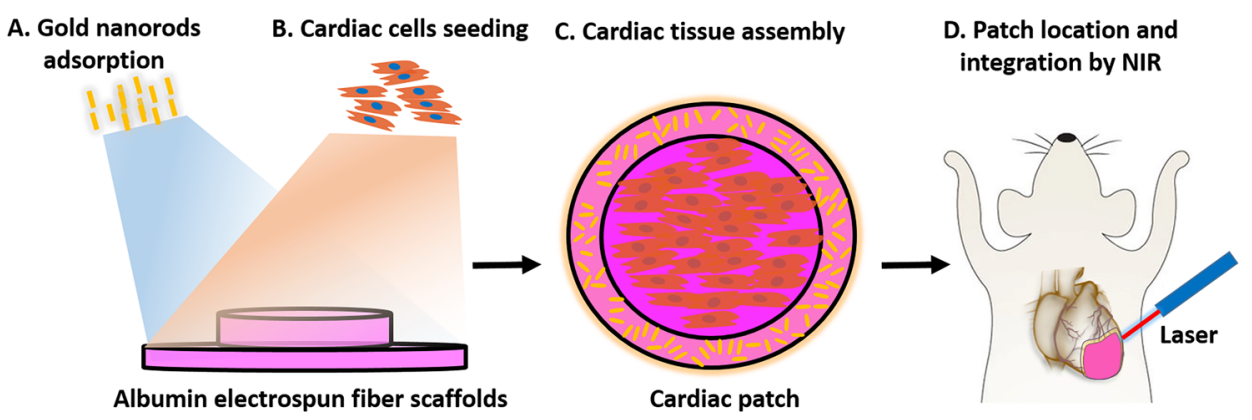

Figure 1. Overview of the concept. (A) Gold nanorods adsorption to albumin electrospun fiber scaffolds. The rods are able to absorb the light and convert it to thermal energy. (B) Cardiac cells are seeded within the nanocomposite scaffolds to form the (C) cardiac patch. (D) After maturation of the tissue, the patch is placed on the heart and irradiated with an $808 \mathrm{~nm}$ laser for suture-free integration.
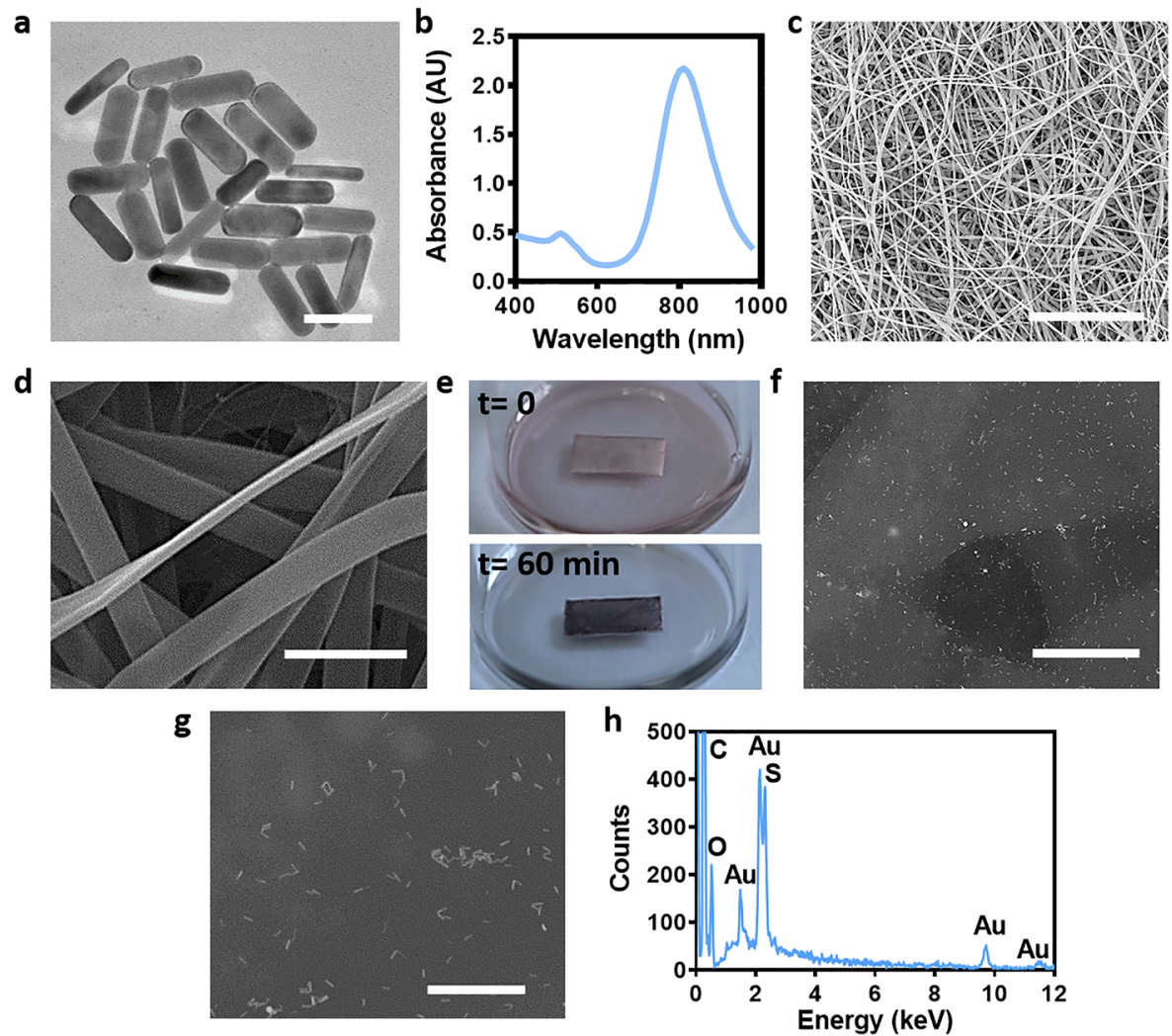

Figure 2. The nanocomposite scaffolds. (a) HRTEM micrographs of AuNRs. Scale bar: $50 \mathrm{~nm}$. (b) UV-Visible-NIR spectra wave scan of AuNRs. (c) SEM micrographs of electrospun albumin fiber scaffolds. Scale bar: $100 \mu \mathrm{m}$. (d) SEM micrographs of electrospun albumin fiber scaffolds. Scale bar: $10 \mu \mathrm{m}$. (e) AuNRs adsorption to electrospun albumin scaffolds at $t=0$ (upper panel) and $t=60$ min (lower panel). (f and g) ESEM micrographs of AuNRs adsorbed to an electrospun albumin fiber scaffold. Scale bars: $\mathrm{f}=2 \mu \mathrm{m}, \mathrm{g}=500 \mathrm{~nm}$. (h) EDX confirming the existence of Au on the albumin fibers.

electrical signal between electrogenic cells. ${ }^{23-26}$ Here, we sought to develop a hybrid scaffold composed of albumin electrospun fibers and gold nanorods (AuNRs). After a functional cardiac patch was engineered within the fibrous scaffold, we exploited the ability of AuNRs to absorb near IR radiation and as a consequence locally heat up. Such irradiation has been previously shown to be highly localized, triggering a temperature raise to $57{ }^{\circ} \mathrm{C}$ in the particle, decaying exponentially within a few nanometers. ${ }^{27}$ This allowed efficient soldering of the engineered tissue with the host (Figure 1) without the need for conventional sutures.

AuNRs were synthesized to allow a rapid and efficient conversion of an $808 \mathrm{~nm}$ laser radiation into thermal energy. The AuNRs were characterized by TEM and UV-vis-NIR spectroscopy. The particles were monodispersed with a mean size of $\sim 60 \mathrm{~nm} \times 20 \mathrm{~nm}$ (Figure 2a). The UV-vis-NIR spectrum of the AuNRs showed a sharp and strong absorption centered at $\sim 810 \mathrm{~nm}$ (Figure $2 \mathrm{~b}$ ). Next, we sought to integrate the AuNRs to 3D albumin electrospun fiber scaffolds, which were previously shown to promote functional cardiac tissue assembly. $^{23}$ Albumin was dissolved in trifluoroethanol and distilled water, and $\beta$-mercaptoethanol was subsequently added after $24 \mathrm{~h}$. The solution was electrospun at room temperature and delivered at a flow rate of $2 \mathrm{~mL} / \mathrm{h}$ under an electrical field of $12.5 \mathrm{kV}$, as described before. ${ }^{28}$ As shown, the scaffold was composed of ribbon-like fibers with a mean width of $2.4 \mu \mathrm{m}$ and a thickness of $0.5 \mu \mathrm{m}$ (Figure $2 \mathrm{c}, \mathrm{d}$ ). Next, we sought to integrate the AuNRs with the protein-based scaffolds. The 

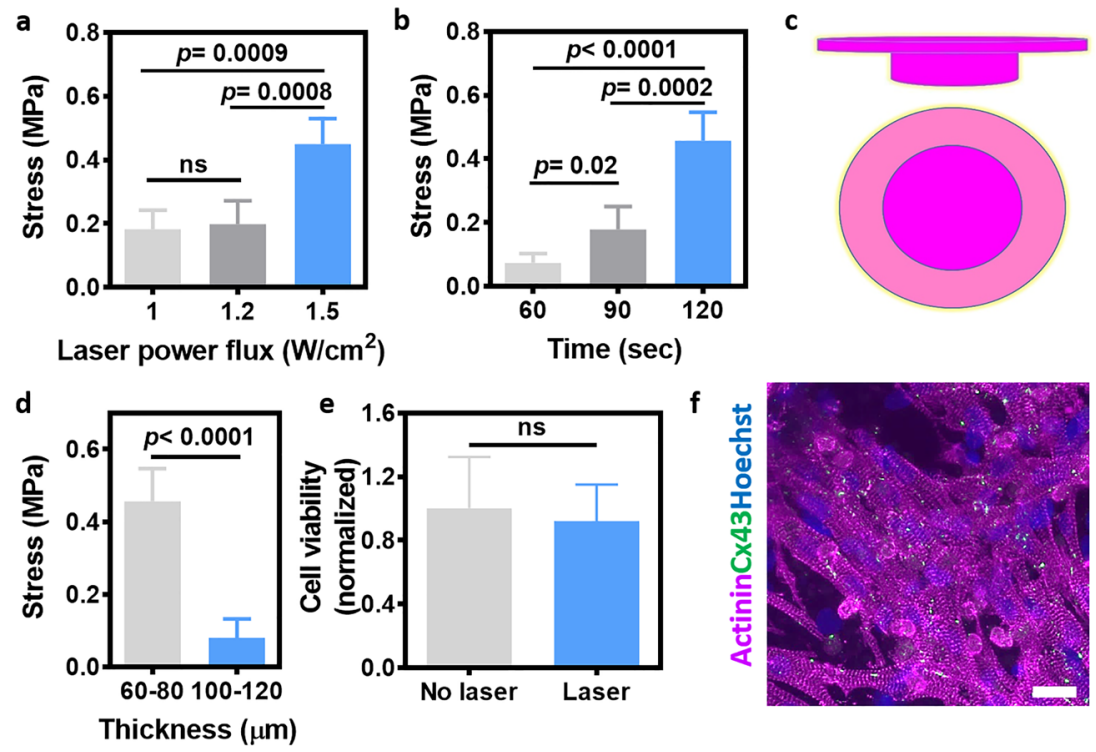

Figure 3. Characterization of the engineered tissue integrated with a porcine cardiac tissue. (a) Stress versus laser power flux. (b) Stress versus time of NIR irradiation. (c) Schematics of the geometry of the albumin fiber scaffold used for tissue welding. (d) Stress versus thickness of albumin scaffold. (e) Cardiac cell viability before and after irradiation. (f) Immunofluorescence image of cardiac $\alpha$-sarcomeric actinin (pink), connexin-43 (green), and cell nuclei (blue). Scale bar: $20 \mu \mathrm{m} . n \geq 10$ in all experiments.
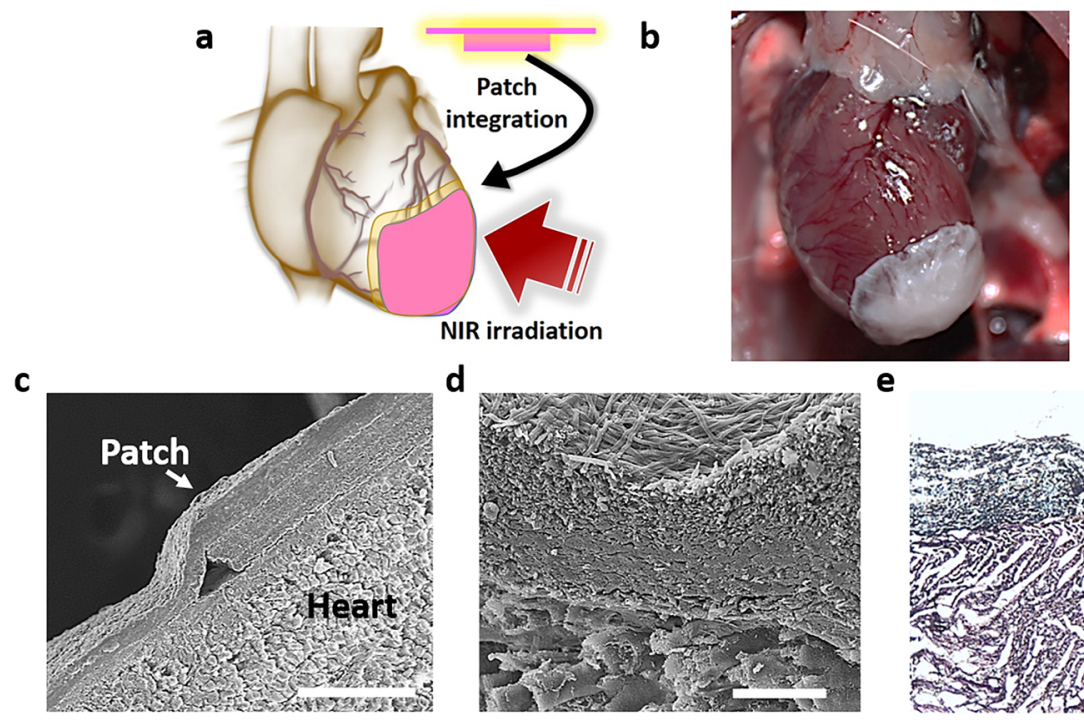

d
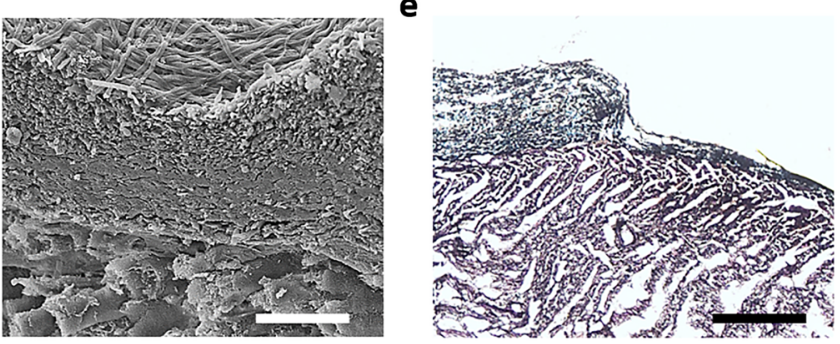

Figure 4. Cardiac patch integration. (a) Schematic representation of the integration process. (b) The cardiac patch after integration with rat heart. (c) SEM micrographs of the cross-section of the heart, revealing the interaction between the patch and the heart. Scale bar: $200 \mu \mathrm{m}$. (d) Higher magnification of the integration point. Scale bar: $50 \mu \mathrm{m}$. (e) H\&E staining of the cross-sectioned heart. Scale bar: $500 \mu \mathrm{m}$.

scaffolds were placed within a AuNRs solution for $60 \mathrm{~min}$ to allow for quick adsorption. As shown, the rods spontaneously attached to the scaffolds leaving a transparent solution and resulting in a brown scaffold (Figure 2e). Surface analysis by scanning electron microscope images and EDX revealed a homogeneous distribution of the AuNRs on the surface of the scaffold fibers (Figure $2 \mathrm{f}-\mathrm{h}$ ).

We next investigated the ability of near IR irradiation to attach the composite scaffolds to pieces of pig myocardium. Several parameters may affect the temperature of the particles in the scaffolds, including the AuNR concentration, laser flux, and time of irradiation. ${ }^{29}$ Therefore, we first sought to examine the laser power flux that was needed to attach the AuNRalbumin electrospun fiber scaffold to the tissue. Fluxes of 1, 1.2, and $1.5 \mathrm{~W} / \mathrm{cm}^{2}$ were applied on thin scaffolds, and a mechanical tester, which pulled the tissue and the scaffold to opposite sides (Supplementary Figure 1), was used to evaluate the adhesion strength between the layers. As shown, a flux of $1.5 \mathrm{~W} / \mathrm{cm}^{2}$ enabled to attach the scaffolds significantly stronger than the 1 and $1.2 \mathrm{~W} / \mathrm{cm}^{2}$ fluxes $(p=0.0009$ and $p=0.0008$, respectively; Figure $3 \mathrm{a})$. We next examined the effect of irradiation time $\left(60,90\right.$, and $120 \mathrm{~s}$, at $\left.1.5 \mathrm{~W} / \mathrm{cm}^{2}\right)$ on the attachment of the scaffolds to the tissue. As shown, a timedependent effect was observed (Figure $3 b$ ) with a significantly stronger attachment after $120 \mathrm{~s}$.

Thick albumin scaffolds do not allow proper penetration of the light through them. Therefore, we designed thick scaffolds with thin edges (Figure 3c). We speculated that the strength of thin layers of albumin scaffolds ${ }^{30}$ would allow to attach the entire patch in place. To evaluate the ability of thin-layer 
scaffolds to attach the tissue, we have fabricated scaffolds with a thickness of $60-80 \mu \mathrm{m}$ or $100-120 \mu \mathrm{m}$. The scaffolds were placed on the tissues and irradiated at $1.5 \mathrm{~W} / \mathrm{cm}^{2}, 120 \mathrm{~s}$. As shown, the $60-80 \mu \mathrm{m}$ scaffolds attached significantly stronger to the tissue, as compared to the 100-120 $\mu \mathrm{m}$ scaffolds (Figure $3 \mathrm{~d} ; p<0.0001$ ), probably due to better penetration of the light.

Near IR irradiation is considered safe for cells and tissues. $^{29,31,32}$ However, we wanted to ensure that the thermal energy generated by the AuNRs after irradiated with near IR for $120 \mathrm{~s}$ at $1.5 \mathrm{~W} / \mathrm{cm}^{2}$ is not affecting the cells. Cardiac cells were isolated from the left ventricles of neonatal rat hearts and seeded within the hybrid scaffolds. After 7 days of incubation, a proper period for cell organization and tissue assembly, the cardiac patches were irradiated. As shown, exposure to near IR did not affect cell viability (Figure 3e). Following tissue irradiation, the patches were fixed and immunostained for cardiac sarcomeric actinin and connexin $43(\mathrm{Cx} 43)$, proteins associated with cell contraction and electrical coupling, respectively. As shown by confocal microscope images (Figure 3f and Supplementary Figure 2), the cardiac cells exhibited massive actinin striation, indicating the ability of the assembled tissue to contract. Furthermore, pronounced $\mathrm{Cx} 43$ expression was observed between the cardiomyocytes, indicating the ability of the cells to function synchronously. Such hallmarks further indicated that the exposure to near IR and the local heating by the AuNRs did not harm the engineered tissue.

We next evaluated the ability of the hybrid scaffolds to attach to the heart in wet and dynamic conditions. Here, the chest of a Sprague-Dawley rat was opened; the heart was exposed, and the hybrid patch was placed on the left ventricle and irradiated with near IR for $120 \mathrm{~s}$ (Figure 4a,b and supplementary movie 1). As shown, the thin edges of the patch adhered to the heart (Figure 4b). Scanning electron microscope images of the sliced heart revealed a tight interaction between the heart and the patch (Figure 4c). Furthermore, as judged by SEM images and $H \& E$ staining of thin sections, the thin edges were able to strongly secure the thick tissue layer to the heart, ensuring a strong fixation (Figure $4 \mathrm{c}-\mathrm{e}$ ). As shown, no changes in the scaffolds' structure could be observed. This further indicates the safety of the procedure. In the future, following implantation, the cells in the nonirradiated locations in the patch will secrete ECM proteins that will further strengthen the integration with the host tissue.

In conclusion, a new hybrid material comprised of fibrous electrospun scaffolds and AuNRs was developed. Upon irradiation with near IR, the particles were locally heated, allowing efficient soldering, perhaps by melting the polymer, or by denaturation of albumin and collagen upon heating and their interlock, ${ }^{33,34}$ providing an elegant, suture-free engraftment of a cardiac patch to the heart. Such technology may assist in the future to integrate various engineered tissues or pure biomaterials with any defected organ, minimizing the risk of additional injury for the patient.

\section{ASSOCIATED CONTENT}

\section{S Supporting Information}

The Supporting Information is available free of charge on the ACS Publications website at DOI: 10.1021/acs.nanolett.7b04924.

Details of other experimental procedures, assessment of tissue adhesion, and immunostaining for actinin and connexin (PDF)
A video displaying cardiac patch integration to the contracting heart (AVI)

\section{AUTHOR INFORMATION}

\section{Corresponding Author}

*E-mail: tdvir@post.tau.ac.il.

ORCID

Tal Dvir: 0000-0002-3153-9928

\section{Author Contributions}

${ }^{\#}$ M.M. and S.F. contributed equally to this work.

\section{Notes}

The authors declare no competing financial interest.

\section{ACKNOWLEDGMENTS}

M.M. was supported by the Colton Family Fellowship. S.F. was supported by the Adams Fellowship Program of the Israel Academy of Sciences and Humanities. T.D. acknowledges support from European Research Council (ERC) Starting Grant 637943, the Slezak Foundation, and the Israeli Science Foundation (700/13). The work is part of the doctoral thesis of M.M. at Tel Aviv University

\section{REFERENCES}

(1) Fleischer, S.; Feiner, R.; Dvir, T. Curr. Opin. Biotechnol. 2017, 47, 23-29.

(2) Ogle, B. M.; Bursac, N.; Domian, I.; Huang, N. F.; Menasché, P.; Murry, C. E.; Pruitt, B.; Radisic, M.; Wu, J. C.; Wu, S. M. Sci. Transl. Med. 2016, 8 (342), 342ps13-342ps13.

(3) Dvir, T.; Timko, B. P.; Kohane, D. S.; Langer, R. Nat. Nanotechnol. 2011, 6 (1), 13-22.

(4) Dvir, T.; Kedem, A.; Ruvinov, E.; Levy, O.; Freeman, I.; Landa, N.; Holbova, R.; Feinberg, M. S.; Dror, S.; Etzion, Y. Proc. Natl. Acad. Sci. U. S. A. 2009, 106 (35), 14990-14995.

(5) Zimmermann, W.-H.; Melnychenko, I.; Wasmeier, G.; Didié, M.; Naito, H.; Nixdorff, U.; Hess, A.; Budinsky, L.; Brune, K.; Michaelis, B. Nat. Med. 2006, 12 (4), 452.

(6) Lee, Y.; Xu, C.; Sebastin, M.; Lee, A.; Holwell, N.; Xu, C.; Miranda Nieves, D.; Mu, L.; Langer, R. S.; Lin, C. Adv. Healthcare Mater. 2015, 4 (16), 2587-2596.

(7) Li, J.; Celiz, A.; Yang, J.; Yang, Q.; Wamala, I.; Whyte, W.; Seo, B.; Vasilyev, N.; Vlassak, J.; Suo, Z. Science 2017, 357 (6349), 378381.

(8) Lauto, A.; Mawad, D.; Foster, L. J. R. J. Chem. Technol. Biotechnol. 2008, 83 (4), 464-472.

(9) Annabi, N.; Tamayol, A.; Shin, S. R.; Ghaemmaghami, A. M.; Peppas, N. A.; Khademhosseini, A. Nano Today 2014, 9 (5), 574-589.

(10) Leggat, P. A.; Smith, D. R.; Kedjarune, U. ANZ. journal of surgery 2007, 77 (4), 209-213.

(11) Mizrahi, B.; Weldon, C.; Kohane, D. S. Tissue adhesives as active implants. Active implants and scaffolds for tissue regeneration; Springer: New York, 2010; pp 39-56.

(12) Jeon, E. Y.; Hwang, B. H.; Yang, Y. J.; Kim, B. J.; Choi, B.-H.; Jung, G. Y.; Cha, H. J. Biomaterials 2015, 67, 11-19.

(13) Lee, H.; Lee, B. P.; Messersmith, P. B. Nature 2007, 448 (7151), 338.

(14) Cho, W. K.; Ankrum, J. A.; Guo, D.; Chester, S. A.; Yang, S. Y.; Kashyap, A.; Campbell, G. A.; Wood, R. J.; Rijal, R. K.; Karnik, R. Proc. Natl. Acad. Sci. U. S. A. 2012, 109 (52), 21289-21294.

(15) Elvin, C. M.; Vuocolo, T.; Brownlee, A. G.; Sando, L.; Huson, M. G.; Liyou, N. E.; Stockwell, P. R.; Lyons, R. E.; Kim, M.; Edwards, G. A. Biomaterials 2010, 31 (32), 8323-8331.

(16) Lang, N.; Pereira, M. J.; Lee, Y.; Friehs, I.; Vasilyev, N. V.; Feins, E. N.; Ablasser, K.; O'Cearbhaill, E. D.; Xu, C.; Fabozzo, A. Sci. Transl. Med. 2014, 6 (218), 218ra6-218ra6. 
(17) Yang, S. Y.; O’Cearbhaill, E. D.; Sisk, G. C.; Park, K. M.; Cho, W. K.; Villiger, M.; Bouma, B. E.; Pomahac, B.; Karp, J. M. Nat. Commun. 2013, 4, 1702.

(18) Mahdavi, A.; Ferreira, L.; Sundback, C.; Nichol, J. W.; Chan, E. P.; Carter, D. J.; Bettinger, C. J.; Patanavanich, S.; Chignozha, L.; BenJoseph, E. Proc. Natl. Acad. Sci. U. S. A. 2008, 105 (7), 2307-2312.

(19) Rose, S.; Prevoteau, A.; Elziere, P.; Hourdet, D.; Marcellan, A.; Leibler, L. Nature 2014, 505 (7483), 382.

(20) Kelmansky, R.; McAlvin, B. J.; Nyska, A.; Dohlman, J. C.; Chiang, H. H.; Hashimoto, M.; Kohane, D. S.; Mizrahi, B. Acta Biomater. 2017, 53, 93-99.

(21) Gobin, A. M.; O'neal, D. P.; Watkins, D. M.; Halas, N. J.; Drezek, R. A.; West, J. L. Lasers Surg. Med. 2005, 37 (2), 123-129.

(22) He, W.; Frueh, J.; Hu, N.; Liu, L.; Gai, M.; He, Q. Advanced Science 2016, 3 (12), 1600206.

(23) Fleischer, S.; Shevach, M.; Feiner, R.; Dvir, T. Nanoscale 2014, 6 (16), 9410-9414.

(24) Shevach, M.; Fleischer, S.; Shapira, A.; Dvir, T. Nano Lett. 2014, 14 (10), 5792-5796.

(25) Baranes, K.; Shevach, M.; Shefi, O.; Dvir, T. Nano Lett. 2016, 16 (5), 2916-2920.

(26) Dvir, T.; Timko, B. P.; Brigham, M. D.; Naik, S. R.; Karajanagi, S. S.; Levy, O.; Jin, H.; Parker, K. K.; Langer, R.; Kohane, D. S. Nat. Nanotechnol. 2011, 6 (11), 720-725.

(27) Lee, S. E.; Liu, G. L.; Kim, F.; Lee, L. P. Nano Lett. 2009, 9 (2), $562-570$.

(28) Fleischer, S.; Shapira, A.; Regev, O.; Nseir, N.; Zussman, E.; Dvir, T. Biotechnol. Bioeng. 2014, 111 (6), 1246-1257.

(29) Timko, B. P.; Arruebo, M.; Shankarappa, S. A.; McAlvin, J. B.; Okonkwo, O. S.; Mizrahi, B.; Stefanescu, C. F.; Gomez, L.; Zhu, J.; Zhu, A. Proc. Natl. Acad. Sci. U. S. A. 2014, 111 (4), 1349-1354.

(30) Dror, Y.; Ziv, T.; Makarov, V.; Wolf, H.; Admon, A.; Zussman, E. Biomacromolecules 2008, 9 (10), 2749-2754.

(31) Cao, J.; Huang, S.; Chen, Y.; Li, S.; Li, X.; Deng, D.; Qian, Z.; Tang, L.; Gu, Y. Biomaterials 2013, 34 (26), 6272-6283.

(32) Zhao, L.; Peng, J.; Huang, Q.; Li, C.; Chen, M.; Sun, Y.; Lin, Q.; Zhu, L.; Li, F. Adv. Funct. Mater. 2014, 24 (3), 363-371.

(33) McNally, K. M.; Sorg, B. S.; Welch, A. J.; Dawes, J. M.; Owen, E. R. Phys. Med. Biol. 1999, 44 (4), 983.

(34) Schober, R.; Ulrich, F.; Sander, T.; Durselen, H.; Hessel, S. Science 1986, 232, 1421-1423. 